\title{
Comparing the value of works of computer painting and traditional painting \\ FEl Chong-zhou
}

(Architecture Department, Sichuan Agricultural University, Chengdu, Sichuan, 610000,

79434920@qq.com)

Keywords: computer painting; traditional painting; value of art works; printing; reproducing

\begin{abstract}
In fine arts teaching, I have exposed myself to traditional painting and the niche, computer painting. I have also applied the two types of tools in my painting practice, and examined the similarities and differences of the two ways and the features of their products. In my teaching, I find out many students are attracted by the new way of expression, some of who even plan to abandon traditional tools and focus on computer painting. Admittedly, with the development of technology, computer painting demonstrates very strong potential in visual expression. The works of computer painting can even compete with traditional fine art to some extent. It is not only more operational, but also evolving into a variety of patterns in expression. However, despite of better attainability in presenting and storing the works, the limitations of computer painting cannot be ignored, which would greatly affect the value of the works. From a comparative perspective, this essay analyzes a few works by various famous artists from different periods and discusses the issues related to the value of computer painting works.
\end{abstract}

\section{The differences and similarities between computer painting and traditional painting}

Computer painting is aided by the techniques and skills through computer, which is very different from frame painting. With the basic painting skills, a painter can also produce a good work through computer. The greatest difference of the two ways of painting lies in genre. Evolving for centuries, traditional frame painting has shifted from the imitation of the explicit figure or form of an object to the expression of the aesthetic emotion of a theme. Taking various approaches, paintings of different genres have been presented. Thus, traditional painting outweighs computer painting in terms of the expressive power and profound meanings. However, immerged in the modern time, computer painting takes certain special techniques and has strong sense of contemporaneity--sharp color, pure and smooth, alluring high gloss, aided by digital techniques - thus makes it more powerful in presenting the texture of the objects.

A definition of computer painting is more close to pop art: popular (designed for the mass), contemporary (short-term plan), easy to be forgotten, cheap, mass production, young (targeted at the youngsters), buckish, sexy, attractive, and in a way of large enterprises. A painting taking a few months, even a few years, can hardly agree with the fast-paced contemporary life. Thus computer painting as a fast culture is more and more welcomed. It can produce real, smooth and steerable color; it is also very convenient to change the color and the figure; replication, enlargement and downsize are more accessible. What is more, the production period is shorter; the words can be easily preserved and transported. On the other hand, we cannot ignore the biggest shortcomings of computer painting: the works relies too much on printing and can be easily replicated (which is a double-edged sword); it can hardly present the texture like frame painting. These fatal shortcomings lead to the difficulty in fully presenting the value of computer paintings.

\section{The features and limitations of computer painting}

In the context of contemporary art, the artiness of art works has been re-defined again and again. To some extent, artiness should serve for the purpose and intention of art, rather than the traditional artiness in form and technique. This shift enables ordinary audience to be able to judge the artiness of a work with instinct, which indicated that contemporary art is more simple and expressive. This also makes contemporary art vulnerable: "it’s too simple”, "without artiness", "everybody can be an 
artist", etc. It is true that compared to traditional painting, computer painting is just like "fast food", i.e. the process of painting is simplified and fast. Without serious techniques in the painting, it is not difficult to imagine the difficult situation of computer painting. What makes it worse is its great reliance on printing, which would even undervalues the works.

Industrialized replication is exactly what frame painting opposes. The fact of replication itself undervalues the actual value (or price), which is unacceptable for any artist. Appreciating a perfect duplicate, you would find it lack of certain elements: an art work only exist in certain space and time, or the uniqueness of it. Without the "uniqueness", an art work is lifeless without its history, which defines the existence of an art work. "History" includes the dimensions of space and time. With the changing of space and time, an art work changes in its physical forms, and also in locations and owners. A typical example is a study on some famous paintings. Researchers would analyze the classic works through chemical or physical approach, which is impossible for an analysis in duplicates. This is also the case when tracking the other two changes, which should be based on the specific status of the original work.

In this sense, the works from computer paintings can never be unique by its nature. The property of computer painting is very obscure. First, it is too close to photography, which was barely accepted as a kind of art. With its various features, however, it was gradually accepted by artists. Even processed by hands, the product of computer painting is still too close to photos. It is thus different from frame painting and includes both the features of photography and frame paintings. Although it benefit from the two forms of art, the obscurity is opposed by artists. Moreover, the essence, or the soul is greatly valued by artists. The original version of a painting has a soul, which can never be replaced by any delicate duplicate. Computer painting is different. The artist has a soul when painting. When the ultimate work always needs to be printed out, it can hardly define the original and the duplicate. In other words, there is no original, not to say a soul, which is the reason why artists can hardly accept this approach. When I am denying the importance and position of computer painting in contemporary art, I have more questions to ask. As a new type of painting, computer painting has a short history. Many new types of art have gone through a lot of difficulties to be accepted by the public. For computer painting, the audience is mostly the youngsters, when the elder generation is hardly exposed to this approach. The most important feature is its simplicity, which enables a fast speech. It is also very powerful in various ways to express different forms or art, which increases its popularity among the young generation. I am afraid it takes a longer period to decide the future of computer painting. Speaking of the masters in the past, Jackson Pollock, for example, was renowned for his spraying painting. If he were alive, would he try to paint with a computer? Computer can imitate the way of spraying and dripping in a faster and economic way. Would Pollock be attracted to take the new way? I do not think so. The more direct human emotion was expressed, the more touching the work will be. When presented through computer, some emotions are filtered. However, he was the master of the past time. With the growing up of e-generation, maybe one day computer painting will replace frame painting. Maybe the human race will be more practical, sensible and hypocritical.

The unique value of original art work is rooted in Theology. Aided by modern techniques, art works come to the era of mechanical replication, which means they were liberated from its reliance on "protocol". This is, to some extent, a kind of development. Since frame painting has ruled the art world for so long, may be its time to give way to a new media?

\section{Conclusion}

With the development of computer painting, more and more artists noticed frame painting's effect on computer painting. More and more traditional painters accepted the approaches taken by computer painting, which has helped with the development of computer painting. Thus, computer painting has greater influence. The young generation is mostly supportive to this new type of painting. May be they are more open to a new media in painting, or they can hardly understand the bonding between artist and frame painting. Whether traditional painting can fully realize its value is not easy to be foreseen. I cannot accept the fact that computer paintings can be exhibited. May be I 
am influenced by the elder generation? It is hard to say.

Eternity and profoundness is cherished in past time; shallow and entertainment will happen in the future. May be the new media will find a better expression in art; may be computer painting will win a place in the world.

\section{Bibliography:}

[1]. AN Jing. Reflection on modern art. Social Sciences Journal of Universities in Shanxi. 2010(8)

[2]. REN Rui. Computer Painting. Central Compilation \& Translation Press. 2010.4

[3]. ZHOU Jie. On the transmission of modern art. Tokyo literature. 2009(1)

[4]. ZHU Qing-hua. Mechanical reproducing and drypoint art. Jounal of Yibin University. 2001(3). 